\title{
THE
}

6-2012

\section{Curriculum and Instructional Methods for Drug Information, Literature Evaluation, and Biostatistics: Survey of U.S. Pharmacy Schools}

Jennifer Phillips

Gabay

Cathy Ficzere

Kristina E. Ward

University of Rhode Island, kward@uri.edu

Follow this and additional works at: https://digitalcommons.uri.edu/php_facpubs

Terms of Use

All rights reserved under copyright.

\section{Citation/Publisher Attribution}

Phillips, J. A, Gabay, M. P., Ficzere, C., \& Ward, K. E. (2012). Curriculum and instructional methods for drug information, literature evaluation, and biostatistics: Survey of U.S. pharmacy schools. Ann Pharmacother 2012; 46:793-801. doi: 10.1345/aph.1Q813

Available at: http://dx.doi.org/10.1345/aph.1Q813

This Article is brought to you for free and open access by the Pharmacy Practice at DigitalCommons@URI. It has been accepted for inclusion in Pharmacy Practice Faculty Publications by an authorized administrator of DigitalCommons@URI. For more information, please contact digitalcommons-group@uri.edu. 
CURRICULUM AND INSTRUCTIONAL METHODS FOR DRUG INFORMATION, LITERATURE EVALUATION, AND BIOSTATISTICS: SURVEY OF US PHARMACY

\section{SCHOOLS}

Authors: Jennifer Phillips PharmD, BCPS

Assistant Professor

Midwestern University Chicago College of Pharmacy

Department of Pharmacy Practice

Michael Gabay PharmD, JD, BCPS

Clinical Associate Professor

University of Illinois at Chicago College of Pharmacy

Department of Pharmacy Practice

Cathy Ficzere PharmD, BCPS

Assistant Professor

Belmont University College of Pharmacy

Department of Pharmaceutical, Social, and Administrative Sciences

Kristina Ward PharmD, BCPS

Clinical Associate Professor

University of Rhode Island College of Pharmacy

Department of Pharmacy Practice

Corresponding author: Michael Gabay PharmD, JD, BCPS

University of Illinois at Chicago College of Pharmacy

833 S Wood St M/C 886 Rm 164

Chicago, IL 60612

The authors report no conflicts of interest.

Key words: drug information, biostatistics, literature evaluation, pharmacy schools 


\section{ABSTRACT}

BACKGROUND: The drug information curriculum in US colleges of pharmacy continues to evolve. The American College of Clinical Pharmacy (ACCP) Drug Information Practice and Research Network (DI PRN) published an opinion paper with specific recommendations regarding drug information education in 2009. Adoption of these recommendations has not been evaluated.

OBJECTIVE: To assess which recommendations made in the ACCP DI PRN opinion paper are included in US pharmacy school curricula and characterize faculty qualifications, educational methods, and recent changes in drug information education.

METHODS: An electronic survey was designed using the ACCP DI PRN opinion paper and the Accreditation Council for Pharmacy Education standards and guidelines for accreditation of PharmD programs in the US. Survey questions addressed curricular content within the following categories: drug information, literature evaluation, and biostatistics. A letter including the online survey link was sent via email to the dean of each US college/school of pharmacy $(\mathrm{N}=128)$. Recipients were instructed to forward the email to the individual at their institution who was the most knowledgeable about the content and methodology used for didactic drug information education.

RESULTS: Sixty-four responses were included in the final analysis. Of the 19 ACCP DI PRN minimum core concepts, 9 (47\%) were included in curricula of all responding institutions; 14 of 19 (74\%) were included in curricula for all but 1 institution. In contrast, 5 of 16 concepts (31\%) were not formally taught by a number of institutions. Many 
respondents noted an increased focus on evidence- based medicine, medication safety, and informatics.

CONCLUSIONS: Although a survey of drug information curricula documented substantial inclusion of the essential concepts presented in the ACCP DI PRN opinion paper, room for improvement remains in drug information curricula in US colleges of pharmacy.

KEY WORDS: biostatistics, drug information, literature evaluation, pharmacy schools. Ann Pharmacother 2012;46:793-801. 


\section{BACKGROUND}

The Accreditation Council for Pharmacy Education (ACPE) is an autonomous and independent agency responsible for the accreditation of professional pharmacy programs. As such, ACPE develops standards and guidelines that aid US pharmacy schools in the development of competent graduates. The most recent ACPE standards state that colleges of pharmacy must ensure that graduates are competent to provide patient-centered and population-based care; manage human, physical, medical, informational, and technological resources; manage medication use systems; and pro- mote availability of health and disease prevention services and health policy. ${ }^{1}$ To achieve these competencies, pharmacy students are exposed to a variety of educational topics in 4 foundational areas: biomedical, pharmaceutical, social/behavioral/administrative, and clinical sciences. Drug information remains a core component of the clinical sciences within the ACPE standards. Students are expected to receive instruction on the fundamentals of drug information practice, study design and methodology, principles and clinical application of primary literature evaluation, evidence-based pharmacy practice, and regulatory and ethical principles of research. In addition, the ACPE standards stress the importance of medication safety and informatics, and these topics are often incorporated into drug information courses.

Over the last 30 years, various surveys have been published that evaluated components of drug information education within US colleges of pharmacy. ${ }^{2-6}$ Kirschenbaum and Rosenberg conducted a survey to determine the scope of drug information educational programs offered by US colleges of pharmacy and drug information centers in $1982 .{ }^{2}$ At that time, 72 colleges of pharmacy were in existence, and the survey had a 93\% response rate. Almost all respondents provided some degree of drug information education. Although only $50 \%$ of baccalaureate degree 
programs offered a formal drug information clerkship, 100\% of doctor of pharmacy (PharmD) programs required a drug information clerkship. Overall, the authors concluded that pharmacy students may not be receiving sufficient drug information training to effectively respond to requests from health care providers and consumers.

Davis and Krucke published the results of a survey of drug information educators at 75 colleges of pharmacy in $1994 .^{3}$ The response rate for the survey was $75 \%$. Eighty- four percent of respondents offered a drug information course of varying credit hours (range 0.5- 4 hours) and 91\% offered some type of drug information clerkship (40-320 hours). Common drug information course objectives included the biomedical publication process; a systematic approach to answering drug information requests; primary, secondary, and tertiary literature; literature evaluation; adverse drug reactions; drug policy management; personal library development; and verbal and written communication techniques. Mullins and colleagues followed with another survey in $1995 .{ }^{4}$ The response rate was $89.2 \%$, and a drug information course director completed $59.1 \%$ of the surveys. Strongly emphasized drug information course topics included the clinical importance of study design, efficient search strategies, types and functions of information resources, oral and written communication skills, and statistical methods. Course topics that were not included in most drug information course curricula were drug utilization evaluation, career opportunities, and library orientation.

A decade later, Cole and Berenson conducted a tele- phone survey that compared drug information practice curriculum components in US colleges of pharmacy. ${ }^{5}$ Eighty- eight colleges of pharmacy were in existence; the phone survey had a response rate of $90 \%$. At that time, $89 \%$ 
of first professional degree programs required at least 1 drug information course and 36\% required 2 such courses. The major topics covered in these didactic courses had not changed substantially from prior surveys; however, there was an increased emphasis on computerized databases and biostatistics. Finally, in 2006, Wang and colleagues published the results of a Webbased survey of 86 colleges of pharmacy (73\% response rate) regarding drug information education and curricula content.6 Results of the survey found that most didactic drug information education was performed as a stand-alone course (70\%); however, con- tent was also integrated within another course or through- out the professional pharmacy program in some schools. Fifty percent of drug information courses included a laboratory or recitation component, which included activities such as advanced literature searching or analysis, answering drug information requests, journal club presentation, medication use evaluation, and monograph preparation.

In 2009, members of the American College of Clinical Pharmacy (ACCP) Drug Information Practice and Re- search Network (DI PRN) published an opinion paper entitled Drug Information: From Education to Practice.7 The purpose of this opinion paper was to (1) describe the role of drug information and the drug information specialist in pharmacy education, (2) describe the role of focused training for specialization, and (3) explain the role, identify challenges, and provide recommendations for drug information specialists in various pharmacy practice settings. With regard to the education of pharmacy school students, the DI PRN developed minimum core drug information concepts that should be formally taught and evaluated in all colleges of pharmacy (Table 1). The aims of our study were to assess the extent to which recommendations made in the ACCP DI PRN opinion paper are included in US pharmacy school curricula and to characterize the qualifications of faculty members involved with drug information education, the types of 
methodology used to deliver drug information education, and recent changes in drug information education.

\section{Methods}

A survey instrument was designed using the ACPE standards and guidelines for accreditation of PharmD programs in the US along with an opinion paper developed by the ACCP DI PRN, which described topics deemed essential for providing PharmD students with the necessary skills in drug information. ${ }^{1,7}$ Although published before the ACCP DI PRN's opinion paper, 2 contemporary surveys regarding the provision of drug information education were consulted to ensure that all aspects of drug information were represented. ${ }^{5,6}$ In addition, the investigators reviewed syllabi from other institutions to ensure that curricula other than those of the investigators' programs were considered. Within the survey, drug information content was defined as information retrieval, references, and the systematic approach to answering drug information questions. In addition to survey questions regarding drug information content, questions concerning coverage of study methodology and biostatistics were included, as some colleges of pharmacy teach these topics as part of an integrated drug information course.

After investigational review board (IRB) approval, a letter was disseminated via email to all deans of pharmacy of all of the colleges listed as having candidate status and above in the American Association of Colleges of Pharmacy (AACP) directory. To increase survey response, the same invitation was sent through the ACCP DI PRN listserv. Email recipients were instructed to forward the survey to the full- time faculty member at their institution who was the most 
knowledgeable about the content and methodology used for didactic drug information education. The survey invitation described the purpose of the study; completion of the survey indicated agreement to participate in the study. The study was granted exempt status through the IRB, as no participant-specific information was obtained. Data were collected using SurveyMonkey. Internet protocol addresses were re- moved from the data after extraction from SurveyMonkey. The respondent was asked to identify the name of the college of pharmacy that they represented to prevent duplicate responses from the same institution. If a duplicate response was received, only the first response was included. Data were deidentified after duplicate responses were removed to ensure anonymity of the response; no comparison between duplicate responses was made.

Information collected through the survey was organized into 4 sections: demographics, methodology of instruction, content of curriculum, and recent changes in either content or methodology of instruction. All questions regarding instructional methodology and curricular content had closed- response options. Closed-response options were used primarily for demographics, instructor qualifications, changes in the last 5 years, and instructional methods used; however, an open-response option was included to capture a wider range of information. To ensure face validity, the investigators administered the survey against the drug information curricula at their institutions. Descriptive statistics were used to summarize information obtained through the survey instrument.

\section{Results}


According to the online AACP directory, 128 colleges of pharmacy were listed at the time the survey was conducted. A total of 71 completed surveys were received. Four survey responses were excluded because they were duplicates. Three survey responses were excluded because they were not completed by full-time faculty members (experiential preceptors, $n=2$; student, $n=1$ ). The total number of responses included in the final analysis was 64 , representing $50 \%$ of pharmacy schools, according to the AACP directory.

\section{Demographics}

Most survey respondents ( $n=45,70 \%)$ were assistant, associate, or full professors at their college of pharmacy and were a course director $(n=38,59 \%)$ in a drug information, literature evaluation, or biostatistics course (Table 2). Most of the survey responses were received from 4 - year programs ( $n=46,72 \%$ ); however, the proportion of 6-year programs was higher in the survey sample com- pared to all US schools8 (23\% vs 5\%, respectively). The geographical distribution of survey responses was similar to that of all pharmacy schools in the US8 (Table 3).

The average age of the responding pharmacy programs was 53 years (range 1-152 years); the average reported class size was 119 (range 51-250). Most survey respondents noted that their institution required students to complete classes on statistics $(n=34,53 \%)$ and computer literacy ( $n=44,69 \%$ ) prior to admission. The majority of survey respondents were from institutions that used a semester system $(n=54,84 \%)$. Only 5 respondents $(8 \%)$ noted that their institution used a quarter system, although some schools used a combination of semester and quarter systems. 
Slightly more than half of all respondents noted that laptops were required for entering first-year pharmacy students at their institution $(n=33,52 \%)$.

\section{Survey Results}

\section{Organization of Content Within the Curriculum}

Many different course combinations were used by respondents (Table 4). A total of 61 respondents answered the survey questions pertaining to drug information, literature evaluation, and biostatistics course format, as well as organization within the curriculum. Survey respondents were asked whether drug information, literature evaluation, and biostatistics were taught as a stand-alone course or a combination course, were integrated throughout the professional program, or were not taught.

Of the 26 respondents who noted that drug information was taught as a stand-alone course, this class was most often offered $(n=19,73 \%)$ in the first professional year. In the majority of cases ( $\mathrm{n}=16,62 \%) 1$ class with a mean of 2.7 (range 1-6) credit hours was offered. Of the 20 respondents who noted that literature evaluation was taught as a stand- alone course, most offered this course in the second $(n=10,50 \%)$ or third $(n=7,35 \%)$ professional years and most $(n=14$, 70\%) offered 1 course with a mean of 2.6 (range 1- 6) credit hours. Of the 19 respondents who noted that biostatistics was taught as a stand-alone course, 8 (42\%) offered this course in the first 
professional year and 8 offered it in the second professional year; most $(n=18,95 \%)$ offered only 1 class, with a mean of 2.4 (range 1-3) credit hours.

A total of 32 respondents noted that combination courses were used to teach drug information, literature evaluation, and biostatistics at their institution. Of the 19 respondents who used a triple combination course (drug information, literature evaluation, biostatistics), most offered this course in the first $(\mathrm{n}=7,37 \%)$ or second $(\mathrm{n}=8,42 \%)$ professional years, with the majority $(\mathrm{n}=$ 13, 68\%) offering 1 class with a mean of 2.8 (range 2-3) credit hours. Of the 8 respondents who noted that their institution used a literature evaluation/biostatistics combination course, most (n $=6,75 \%)$ offered it in the third professional year with the majority $(n=6,75 \%)$ offering 1 class, with a mean of 2.9 (range 2- 4) credit hours. Of the 5 respondents who noted that their institution used a drug information/literature evaluation combination course, most $(n=3,60 \%)$ offered it in the second professional year; all offered 1 class with a mean of 2.8 (range 2-3) credit hours.

\section{Instructional Methodology}

Survey respondents were asked to denote how drug in- formation, literature evaluation, and biostatistics are taught at their institution. Specifically, they were asked to denote the percentage of hours dedicated to the following formats of teaching: didactic lecture, small group learning, Internet- based learning, or another unspecified format. The response rates for each format varied according to format; 59 responses were received for the didactic lecture format, 57 for the smallgroup format, 52 for the Internet-based activity for- mat, and 37 for the other format. As shown 
in Figure 1, most respondents who used didactic lectures $(n=31,52.5 \%)$ used didactic lecture for $50 \%$ or less of the lecture hours.

A total of 57 (89\%) respondents indicated that small- group learning was used, with most of these respondents ( $n=52,91 \%$ ) using $50 \%$ or less of available class hours for this format. For those using small-group learning, the 2 most common topics covered in the small-group sessions were literature evaluation/journal club $(n=48,84 \%)$ and drug information references $(n=42,74 \%)$. Other topics covered included EndNote, PubMed, plagiarism, peer review, team- based learning, drug information consults, levels of evidence, and verbal responses to drug information questions. For the small-group learning activities, respondents were asked to denote the qualifications of the individual(s) facilitating the sessions. A total of 56 respondents answered this question. Most respondents noted that drug information faculty and other pharmacy practice faculty were involved in facilitating (73\% and 61\%, respectively), although 18\% indicated that nonpharmacy practice faculty members were used as well. With regard to students and residents serving as facilitators, 32\% of respondents noted the use of postgraduate year 1 (PGY1) residents, 14\% used postgraduate year 2 (PGY2) drug information residents, 4\% used PGY2 residents (in specialty areas other than drug information), and 23\% used students. Respondents were asked to denote the types of activities performed by the small-group facilitator. A total of 50 (89\%) respondents selected workshop facilitation, 35 (63\%) selected workshop grading, and 17 (30\%) selected workshop writing/development. Other tasks mentioned included journal club evaluation, computer-based activities, and evaluating self-study drug information questions. 
A total of 44 (69\%) respondents indicated that they used the Internet as a form of instructional methodology. Examples of content covered in Internet-based activities include drug information resources on the Internet, PubMed, plagiarism, research ethics, biostatistics support, guidelines, and online journal clubs.

Survey respondents were asked to note the quantity and type of assignments used in courses teaching drug information, literature evaluation, and biostatistics, as well as to specify whether the assignments were for individuals or groups; 61 respondents answered this series of questions. All noted that students were required to complete at least 1 mandatory assignment. The mean number of assignments given to students was 8.7 (range 1-35). The most frequently used assignments as noted by survey respondents were individual drug information reference assignments ( $n=45,74 \%)$, individual PubMed searching assignments ( $=44,72 \%)$, group journal club/literature evaluation exercises $(n=42,69 \%)$, individual drug information papers/consultations $(\mathrm{n}=39,64 \%)$, and group drug information reference assignments $(\mathrm{n}=28$, 46\%). Survey respondents were also asked to denote what type(s) of technology were used to teach drug information, literature evaluation, and biostatistics at their institution. Fifty-nine respondents answered this series of questions. Table 5 lists the types of technology reported by respondents. Most $(n=56,95 \%)$ respondents noted the use of an online course management program. Slightly more than half $(\mathrm{n}=36,61 \%)$ used an audience response system. YouTube, online blogs, twitters, and wikis were also used by some respondents to teach this content.

Faculty and Course Directors 
Survey respondents were asked to indicate how many full- time equivalents (FTEs) their institution allocated to teach drug information, literature evaluation, or biostatistics. A total of 62 respondents answered this question. Overall, 39 of 62 (63\%) respondents noted that at least 1 FTE was allocated for this content. The mean number of allocated FTEs reported was 1.8 (range 0.5-8.1). For schools with a reported enrollment of more than 100 students $(n=31), 21(68 \%)$ survey respondents indicated that their institution allocated at least 1 FTE for a drug information faculty member; the mean number of FTEs reported was 2.3. For schools with a reported enrollment of less than 100 students $(n=21), 10(48 \%)$ reported allocating at least 1 FTE; the mean number of FTEs was 1.1.

Survey respondents were asked to denote the number of faculty members (regardless of specialty) needed to teach courses in drug information, literature evaluation, and bio- statistics. A total of 59 individuals responded to this series of questions. The mean number of didactic instructors reported needed was 4 (range 1-15). The mean number of small-group facilitators used was 3.8 (range 1-20). The qualifications of faculty needed to teach drug information, literature evaluation, and biostatistics courses are depicted in Figure 2. Most of the respondents indicated that at least 1 of the faculty members teaching drug information and literature evaluation had a doctorate degree in pharmacy (97\% and 90\%, respectively). Slightly more than half of all respondents noted that at least 1 faculty member teaching drug information and literature evaluation had completed a specialized residency in drug information (64\% and 58\%, respectively). For the bio- statistics courses, slightly more than half of all respondents noted that at least 1 faculty member had either a PhD or a PharmD degree (57\% for each), and only 39\% indicated that at least 1 faculty member had completed a specialized residency in drug information. 


\section{Content of Curriculum}

A total of 19 criteria described as being essential to all pharmacy curricula in the DI PRN opinion paper were evaluated for inclusion within the curriculum. Nine (47\%) criteria were covered in the curricula of all colleges of pharmacy rep- resented in this survey; 14 of 19 (74\%) were covered by all but 1 college of pharmacy, and 5 of 19 (26\%) were identified as not being taught by a number of colleges of pharmacy. The areas taught by $100 \%$ of respondents and the top areas identified as not being taught are included in Table 6.

Survey respondents were asked to identify what type of changes were made within the last 5 years to the content and instructional methodology of courses teaching drug information, literature evaluation, and biostatistics. A total of 59 respondents answered this series of questions. Responses are summarized in Figure 3. Most $(n=39,66 \%)$ indicated an in- creased focus on evidence-based medicine (EBM). Slightly less than half of all respondents noted that less emphasis was placed on print resources $(n=27,46 \%)$. Other common changes identified were more focus on informatics and medication safety. For changes in instructional methodology, most respondents ( $\mathrm{n}=45,76 \%)$ noted greater use of active learning strategies. Other responses included more workshops ( $\mathrm{n}=25,42 \%)$ and incorporating technology into the learning process (n = 15, 25\%).

Survey respondents were asked to identify the top 3 areas, in their opinion, in which students struggle in drug information, literature evaluation, and biostatistics courses. A total of 60 respondents answered this series of questions. The 3 areas identified were critically evaluating 
the medical literature $(n=44)$, summarizing basic biostatistics and research design $(n=27)$, and creating effective and efficient literature search strategies $(n=25)$. When asked what has been done to in- crease student understanding in these areas, the most frequent response $(n=32)$ was to increase the number of practice opportunities available to students.

\section{Discussion}

The original goal of this survey was to assess the extent to which the recommendations made in the 2009 ACCP DI PRN opinion paper are incorporated into the curricula of pharmacy schools. While it was hoped that survey responses would be received from more than $50 \%$ of schools, the data obtained have provided insight into the curricular structure and instructional methodology used in drug information education. Several combinations of responses and pathways had to be created within the survey instrument to accommodate a variety of responses regarding curricular design and topic location. It is hoped that all questions were clear and that the entire range of responses was present; however, some variations in curricula may not have been anticipated. Although we requested that the most knowledgeable faculty member complete the survey, we could not verify that the request was honored, since we maintained institutional anonymity.

Survey results revealed that $47 \%$ of all essential or core drug information concepts are covered by all institutions responding to the survey and that $74 \%$ are covered by almost all respondents. However, there is still room for improvement, since $26 \%$ of essential core concepts, as outlined in the 2009 DI PRN opinion paper, are not formally being taught by a number of institutions. Most of the criteria outlined in the opinion paper are also included in the ACPE requirements. 
However, some items (eg, counterdetailing industry and evaluating marketing materials) not listed in ACPE requirements were deemed by the authors of the opinion paper to be fundamental to pharmacy practice. Both of these areas were identified as not being taught by a number of institutions. Course directors should consider adding these concepts to allow graduates to interact in a more meaningful way with members of the pharmaceutical industry. This will also position pharmacy school graduates to provide more meaningful assistance to patients who may present with questions about advertisements they see in print, on television, or on the Inter- net.

The DI PRN opinion paper recommended that at least 1 FTE be allocated to an individual specializing in drug information. The results of this survey indicated that $63 \%$ of all survey respondents had at least 1 FTE allocated. Most faculty members teaching drug information (96\%) and literature evaluation (90\%) have a PharmD degree and most (64\% and 56\%, respectively) have completed a drug information residency. More faculty members with a $\mathrm{PhD}$ are involved with teaching the biostatistics component of the curricula than with drug information or literature evaluation, which is likely a reflection of the expertise obtained during doctoral training.

The results of this survey indicate that a variety of different formats are being used to deliver drug information education in addition to the traditional didactic lecture format. In fact, most respondents indicated that they use less than $50 \%$ of their available course hours for didactic lectures. The remainder of available course hours is being used for small- group workshops, active learning opportunities, and Internet- based activities. Whether or not this shift away from the traditional didactic lecture towards more active learning opportunities has led to improvements in student learning is not known and is an area for future pedagogical research. 
Many colleges of pharmacy are adapting curricula to better prepare graduates to function competently in the cur- rent health care environment. Many institutions noted that they have placed a greater focus on EBM and some have in- creased their focus on medication safety and pharmacy informatics; these 3 areas have become mainstream in pharmacy practice. By providing pharmacy students with more education in these areas, pharmacy educators are better preparing students to function in today's health care setting.

Our survey regarding drug information, literature evaluation, and biostatistics content in pharmacy curricula documented substantial inclusion of specific topics considered essential in accordance with the ACCP DI PRN opinion paper. However, several topics have not been incorporated into curricula. Most pharmacy programs devote at least 1 FTE to drug information education, as recommended in the opinion paper. Increased use of innovative teaching strategies over traditional lecture format was found; future investigation to document the effectiveness of newer teaching strategies in drug information, literature evaluation, and biostatistics is warranted. 


\section{REFERENCES}

1. Accreditation Council for Pharmacy Education. Accreditation standards for the professional program in pharmacy leading to the doctor of pharmacy degree. Available from http://www.acpe-accredit.org/pdf/FinalS2007Guidelines2.0.pdf. (accessed 2011 Dec 27).

2. Kirschenbaum HL, Rosenberg JM. Educational programs offered by colleges of pharmacy and drug information centers within the United States. Am J Pharm Ed 1984;48:155-57.

3. Davis SK, Krucke LB. Drug information training and experience at U.S. schools of pharmacy. Am J Pharm Ed 1994;58:157-64.

4. Mullins B, D’Elia RP, Barnes CL, Fleming CM. Comparison of drug information course curricula in schools and colleges of pharmacy. Am J Pharm Ed 1995;59:55-59.

5. Cole SW, Berensen NM. Comparison of drug information practice curriculum components in US colleges of pharmacy. Am J Pharm Ed 2005;69:240-44.

6. Wang F, Troutman WG, Seo T, Peak A, Rosenberg JM. Drug information education in doctor of pharmacy programs. Am J Pharm Ed 2006;70:1-7.

7. Bernknopf AC, Karpinski JP, McKeever AL, et al. Drug information: from education to practice. Pharmacotherapy 2009;29:331-46.

8. Pharm.D. Degree Programs Anticipated for 2012-13. Pharmacy School Admission Requirements. American Association of Colleges of Pharmacy. www.aacp.org/resources//student/pharmacyforyou/admissions/pages/PSAR.aspx. Accessed February 4, 2012. 
Table 1. ACCP DI PRN minimum core concepts for drug information education (Bernknopf 2009).

- Applying medical information to specific patient situations.

- Counter-detailing and appropriate interactions with the pharmaceutical industry.

- Creating effective literature search strategies.

- Critical evaluation of marketing and promotional materials/advertisements.

- Describing the drug regulation process.

- Distinguishing statistical versus clinical significance.

- Discerning/communicating appropriate information to patients.

- Evaluating drug use policies and procedures.

- Identifying, evaluating, and utilizing key print sources.

- Identifying, managing, reporting, and preventing adverse drug events.

- Incorporating principles and practices of evidence-based medicine into pharmaceutical care.

- Locating and critically evaluating medical information on the Internet.

- Preparing, presenting, and participating in journal clubs.

- Providing verbal and written responses to drug information requests.

- Summarizing basic biostatistics and research design.

- Understanding creation/management of a drug formulary.

- Using electronic databases/other references in an effective manner. 
Table 2. Survey Respondents ( $\mathrm{n}=64$ )

\begin{tabular}{lcc} 
Assistant, Associate, or Full Professor & 45 & $70 \%$ \\
Course Director & 38 & $59 \%$ \\
Instructor & 23 & $36 \%$ \\
Other & 7 & $11 \%$ \\
Chair / Vice Chair & 4 & $6 \%$ \\
Assistant/Associate Dean & 4 & $6 \%$ \\
\hline
\end{tabular}


Table 3. Characteristics of Surveyed and All PharmD Programs Enrolling for 2012-2013

\begin{tabular}{lcccc}
\hline Program Type & \multicolumn{2}{c}{ Surveyed (n=64) } & & \multicolumn{2}{c}{ All (n=124) } \\
\cline { 2 - 5 } 4-year & 46 & $76 \%$ & 104 & $84 \%$ \\
6-year & 15 & $23 \%$ & 11 & $9 \%$ \\
3-year (accelerated) & 3 & $5 \%$ & 12 & $10 \%$ \\
Region & & & & \\
South & 24 & $38 \%$ & 47 & $38 \%$ \\
Midwest & 16 & $25 \%$ & 29 & $23 \%$ \\
West & 13 & $20 \%$ & 23 & $19 \%$ \\
Northeast & 8 & $13 \%$ & 24 & $19 \%$ \\
Other & 1 & $2 \%$ & 1 & $<1 \%$ \\
\hline
\end{tabular}


Table 4. Distribution of Drug Information, Literature Evaluation, and Biostatistics Curriculum

\begin{tabular}{|c|c|c|c|c|}
\hline Courses/Course Combinations & $\underline{\mathbf{n}}$ & $\begin{array}{l}\text { Credit Hours } \\
\text { Mean (Range) } \\
\end{array}$ & Single Class & $\frac{\text { Most Common }}{\text { Curricular Position(s) }}$ \\
\hline Drug Information (alone) & 26 & $2.7(1-6)$ & $16(62 \%)$ & First year: 19 \\
\hline Literature Evaluation (alone) & 20 & $2.6(1-6)$ & $14(70 \%)$ & $\begin{array}{l}\text { Second year: } 10 \\
\text { Third year: } 7\end{array}$ \\
\hline Biostatistics (alone) & 19 & $2.4(1-3)$ & $18(95 \%)$ & $\begin{array}{l}\text { First year: } 8 \\
\text { Second year: } 8\end{array}$ \\
\hline $\begin{array}{l}\text { Drug Information, Literature } \\
\text { Evaluation, and Biostatistics }\end{array}$ & 19 & $2.8(2-3)$ & $13(68 \%)$ & $\begin{array}{l}\text { First year: } 7 \\
\text { Second year: } 8\end{array}$ \\
\hline $\begin{array}{l}\text { Literature Evaluation and } \\
\text { Biostatistics }\end{array}$ & 8 & $2.9(2-4)$ & $6(75 \%)$ & Third year: 6 \\
\hline $\begin{array}{l}\text { Drug Information and Literature } \\
\text { Evaluation }\end{array}$ & 5 & $2.8(2-3)$ & $3(60 \%)$ & Second year: 3 \\
\hline
\end{tabular}


Figure 1. Reported Proportion of Classroom Hours Used for Didactic Lecture, Small Groups, and Internet-Based Activity ( $\mathrm{n}=59)$

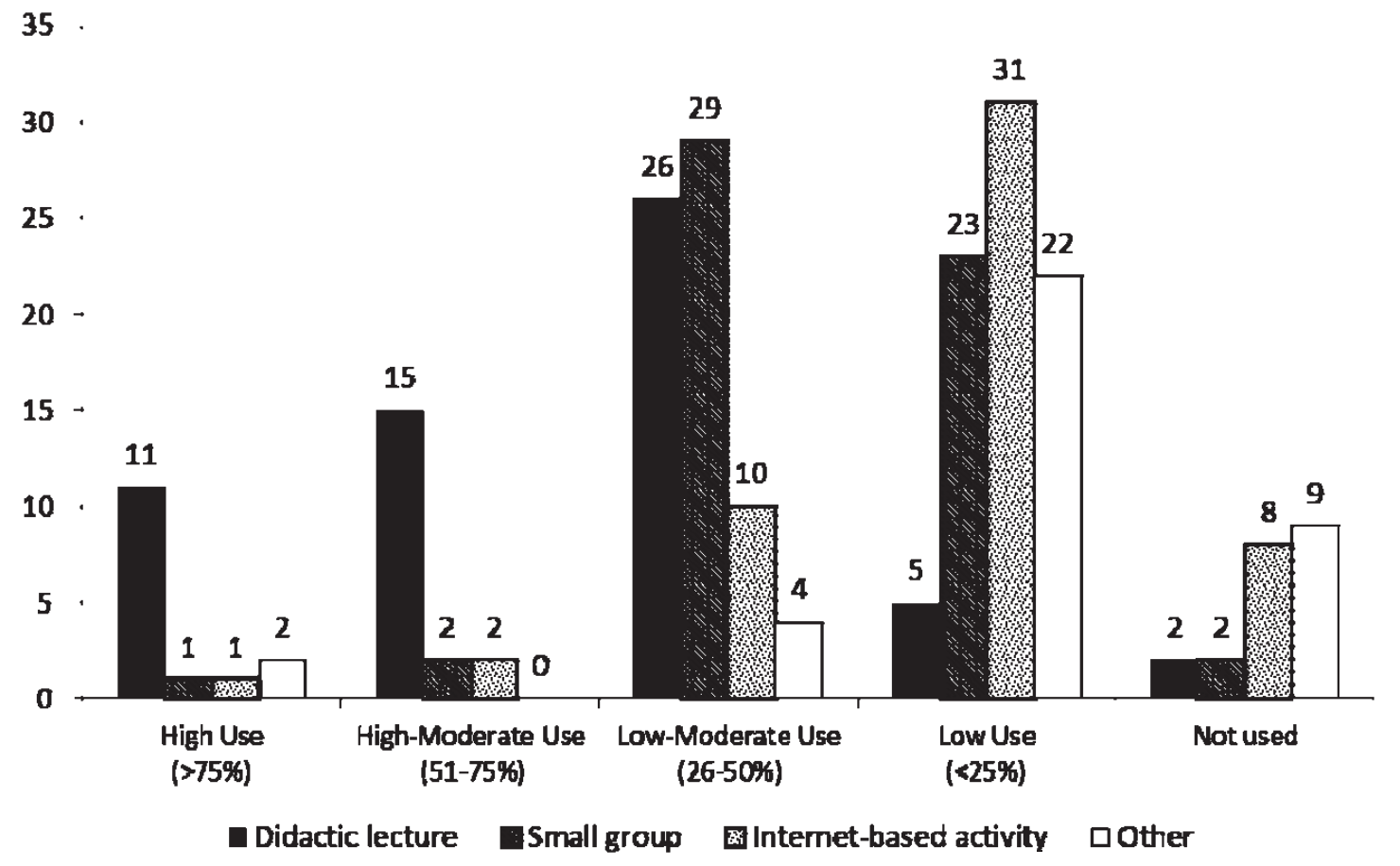


Figure 2. Qualifications of Faculty Teaching Drug Information, Literature Evaluation, and Biostatistics $(n=56)$

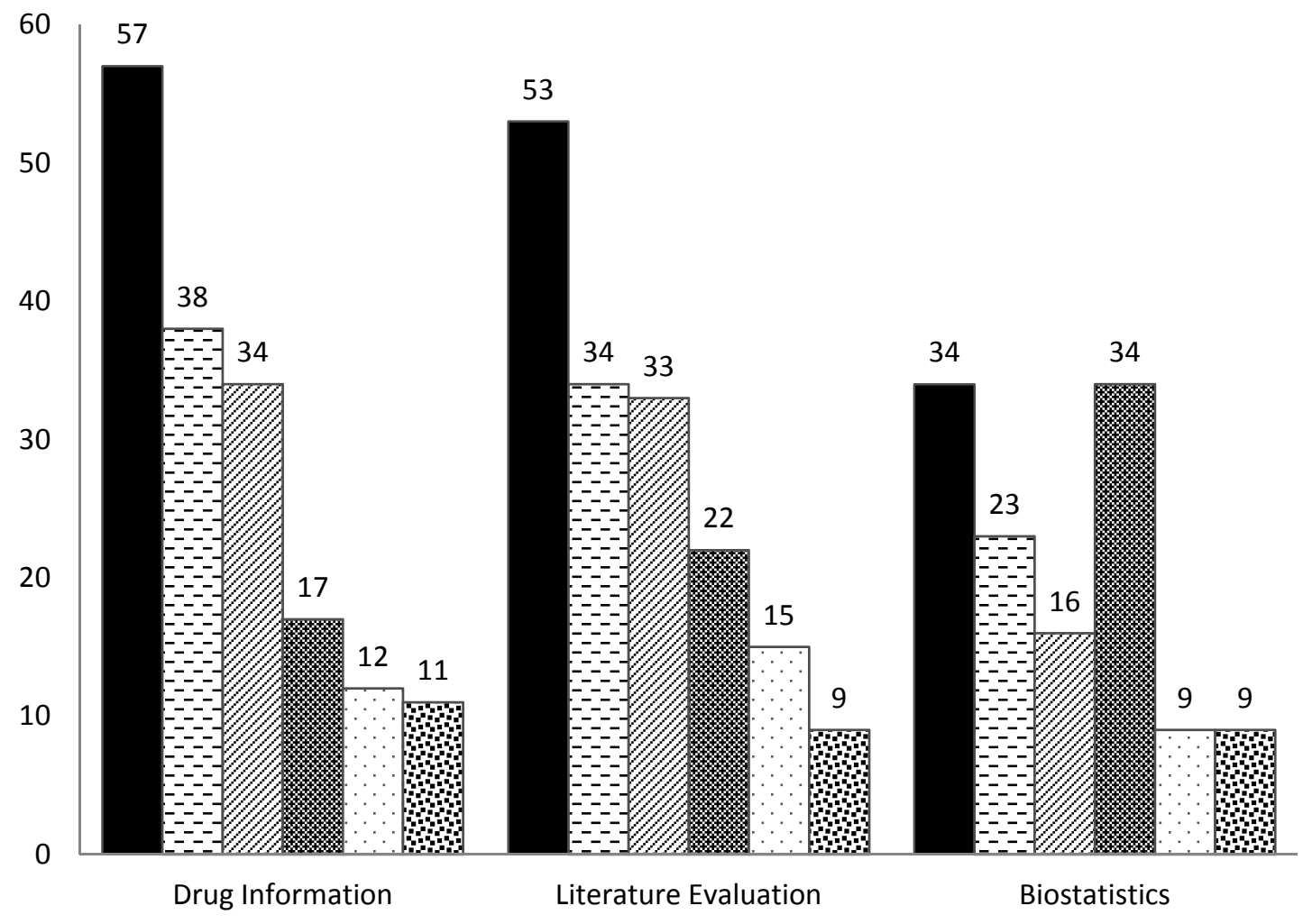

nPharmD $\boxminus D I$ Residency $\because$ PGY-1 PhD $\square$ Specialty Residency Other 
Figure 3. Recent Changes to the Drug Information Curriculum (n=59)

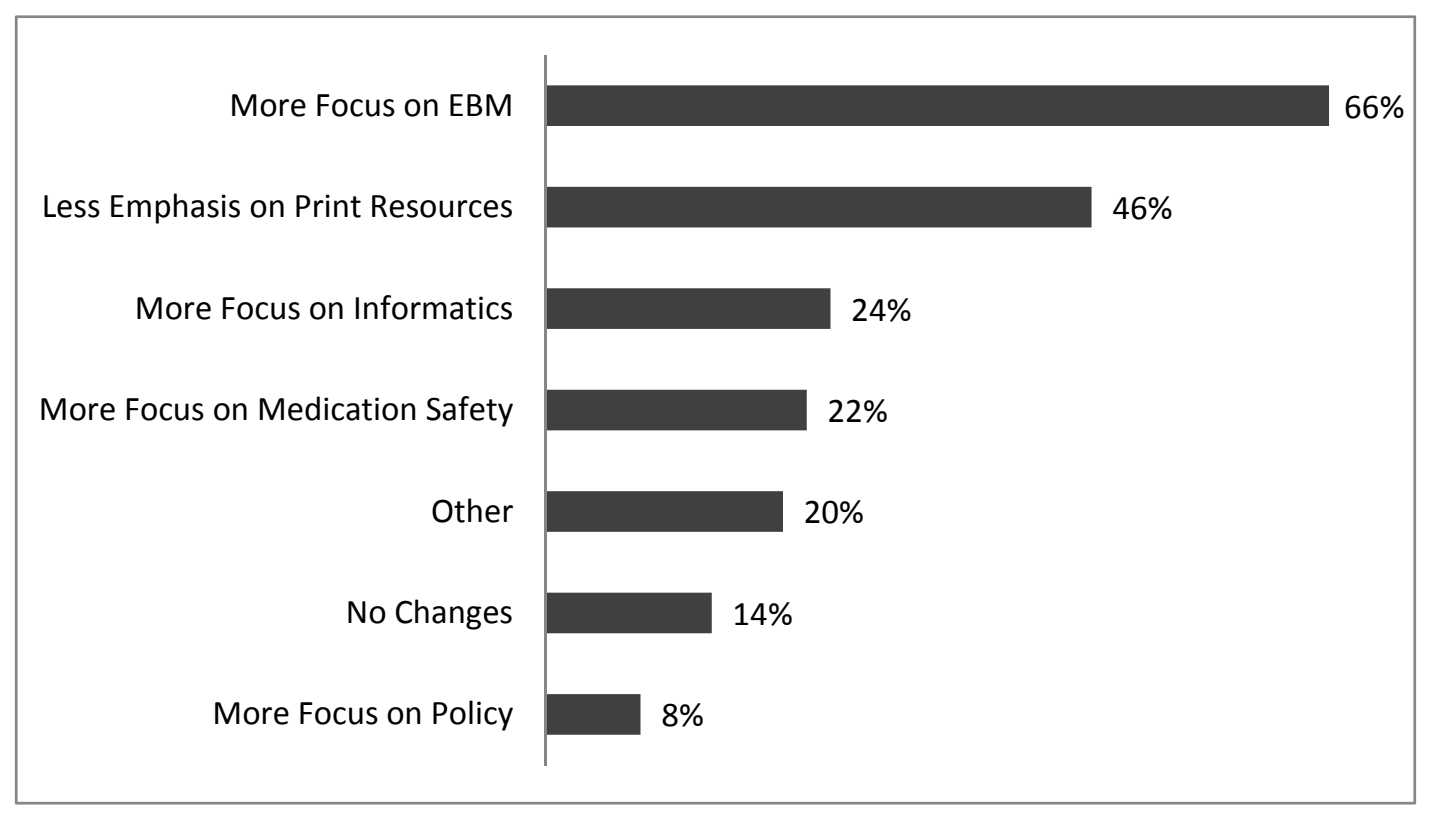


Table 5: Technology Used to Instruct in Drug Information, Literature Evaluation, and Biostatistics Courses. $(\mathrm{n}=56)$

\section{Technology}

On-line course management

Audience response systems

YouTube

On-line blogs

Twitter

Wikis

Facebook

\section{n (\%)}

56 (95\%)

36 (61\%)

8 (14\%)

$5(8 \%)$

$2(3 \%)$

$2(3 \%)$

0 
Table 6: Content of Curriculum

\section{Taught by $100 \%$ of respondents}

- Discerning and communicating essential health information for patient education

- Journal club

- Literature evaluation

- Literature searching

- Medication safety (adverse drug reactions, medication errors, quality improvement

- Statistical vs. clinical significance

- Summarizing basic biostatistics

- Using print resources effectively

- Verbal and written responses to drug information questions

Top areas identified as "not taught"

- Counter-detailing industry

- Drug use policies \& procedures

- Evaluating marketing materials

- Formulary management

- Pharmacy informatics 